\title{
Resources and Environmental Carrying Capacity Using RS and GIS
}

\author{
Shi-Xin Wang ${ }^{1}$, Ming Shang ${ }^{1}$,*, Yi Zhou ${ }^{1}$, Wen-Liang Liu', \\ Feng Wang ${ }^{1}$, Li-Tao Wang ${ }^{1}$ \\ ${ }^{1}$ Institute of Remote Sensing and Digital Earth, Chinese Academy of Sciences, Beijing 100101, China \\ ${ }^{2}$ University of Chinese Academy of Sciences, Beijing 100049, China
}

Received: 15 March 2017

Accepted: 4 May 2017

\begin{abstract}
Evaluating resources and environmental carrying capacity (RECC) plays an important role in sustainable regional development. Using the urban agglomerations of Beijing, Tianjin, and Hebei Province as examples, in this paper we utilize remote sensing (RS) and geographic information system (GIS) techniques to study RECC. Based on data obtained from statistical information and RS technology, we selected 22 indicators with which to construct an RECC evaluation scheme. Then we conducted a mean-variance analysis to determine the weight of each indicator. Finally, we calculated the RECC of each city in the study area and statistically analyzed the main factors influencing RECC. Our results indicate that:

- The environment carries the most weight in RECC assessments, followed by resources, economic, and infrastructure

- In the study area, the RECC ranking is as follows: Beijing, Tianjin, Chengde, Langfang, Qinhuangdao, Cangzhou, Shijiazhuang, Tangshan, Baoding, Zhangjiakou, Hengshui, Handan, Xingtai

- Geographically, the eastern and central regions have higher RECC than the southern and northeast regions

- A region's per capita fiscal income is the most important factor affecting its RECC
\end{abstract}

Keywords: resources and environmental carrying capacity, remote sensing, mean-variance method

\section{Introduction}

With respect to industrialization and urbanization, China's economy is presently in a period of stable and rapid development. However, this economic and population growth brings with it a range of problems such as resource shortages and environmental pollution. As such, it is necessary to better understand the resources-

*e-mail: shangming@radi.ac.cn population-environment relationship, and the "carrying capacity" concept offers a way of thinking about sustainable development.

The carrying capacity concept was originally derived in the field of ecology [1]. Since that time, numerous and varied theories of carrying capacity have been developed based on different requirements [2-8], and these studies have imbued the concept with a breadth and depth of meaning. In China, the resources and environmental carrying capacity (RECC) concept was first introduced in 1991 by scientists who had used this concept in a report 
titled "The Fujian province Meizhou Bay development zone environmental planning comprehensive research" [9]. Subsequently, many studies have been conducted to analyze RECC [10-12]. However, despite the fact that some researchers have used geographic information system (GIS) to analyze carrying capacity [13-15], most studies have used only statistical data to assess RECC, and a few have utilized remote sensing (RS) data.

In this study, using statistical and RS data, we evaluated the RECC of the urban agglomerations of Beijing, Tianjin, and Hebei Province. These crucial economic urban agglomerations in northern China are often characterized by fog and hazy weather conditions. As such, investigating the RECC of this area will have important practical significance for its sustainable development, as well as providing guidance for other regions.

\section{Study Area and Data Sources}

The study area is located in Northern China between longitudes $113.08^{\circ}-119.87^{\circ} \mathrm{E}$ and latitudes $36.03^{\circ}$ $42.62^{\circ} \mathrm{N}$ (Fig. 1), and has an area of $21.8 \times 10^{4} \mathrm{~km}^{2}$. It consists of two municipalities directly under the central government (Beijing and Tianjin) and 11 prefecturelevel cities (Baoding, Langfang, Tangshan, Zhangjiakou, Chengde, Qinhuangdao, Cangzhou, Hengshui, Xingtai, Handan, and Shijiazhuang).

In this study we used both statistical and RS data. We obtained 2014 statistical data from the Beijing Statistical Yearbook 2015, Tianjin Statistical Yearbook 2015, Hebei Economic Yearbook 2015, and China City Statistical Yearbook 2015. The RS data we utilized:

MOD04_L2-MODIS/Terra Aerosol 5-Min L2 Swath 10 $\mathrm{km}$ aerosol products.

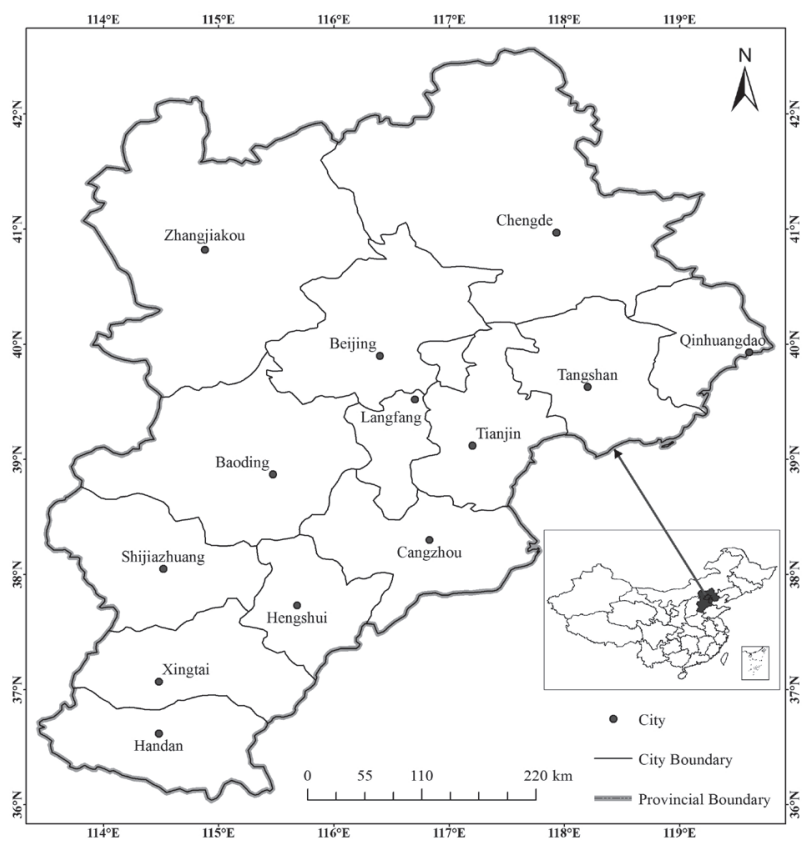

Fig. 1. Location of study area.
National Polar-orbiting Partnership-Visible Infrared Imaging Radiometer Suite (NPP-VIIRS) nighttime lights data.

Defense Meteorological Satellite Program Operational Linescan System (DMSP-OLS) nighttime lights data.

MOD13A3 normalized difference vegetation index (NDVI) products.

Landsat8-Operational Land Imager (OLI) products. All of these data were observed in 2014, except the Landsat8OLI product, which contains data observed in 2013 due to several poor-quality images in 2014.

We downloaded the aerosol products from ladsweb. nascom.nasa.gov, the nighttime lights data from ngdc. noaa.gov/eog, and the vegetation index and Landsat8-OLI products from glovis.usgs.gov.

\section{Methods}

\section{RS Data Processing}

\section{Aerosol Optical Depth (AOD) and NDVI}

To determine the annual mean aerosol optical depth (AOD) values, we applied the following procedures:

1. Used the MODIS reprojection tool (MRT) to resample and generate a mosaic from the original AOD imagery.

2. Extracted the AOD data of the study area using ArcGIS 10.3 software.

3. Used the ordinary kriging technique to interpolate values when AOD values were missing within the study area.

4. Lastly, we calculated the mean annual AOD using ArcGIS software.

We followed the same procedures used for the AOD products with the NDVI products, except for step No. 3, above, since there were no missing values in the NDVI products.

\section{NPP-VIIRS Data}

Since the original NPP-VIIRS data have not been filtered to eliminate noise such as lights from fires, bright surfaces, and other temporal lights, they cannot exactly identify human socioeconomic activities. Here, to correct the NPP-VIIRS data, we utilized a method proposed by Shi et al. [16], which consists of three steps:

1. Assuming that the 2013 DMSP-OLS imagery and the 2014 NPP-VIIRS imagery had the same areas that were lit up, we applied the DMSP-OLS imagery to correct the NPP-VIIRS imagery.

2. Then we created a mask in which pixels with positive digital number (DN) values in the DMSP-OLS imagery were assigned a value of 1 and we overlaid this mask with NPP-VIIRS imagery to obtain an initial corrected NPP-VIIRS imagery.

3. Unlike Shi et al. [16], we chose a reasonable threshold from the four most-developed megacities (Beijing, 
Table 1. Indicator system.

\begin{tabular}{|c|c|c|c|c|}
\hline Sector & Indicator & Unit & Attribute & Data source \\
\hline \multirow{5}{*}{ Resources } & 1) Precipitation & $\mathrm{mm}$ & + & SY \\
\hline & 2) Per capita constructive land & $\mathrm{m}^{2}$ & + & RS \\
\hline & 3) Per capita cultivated area & $\mathrm{m}^{2}$ & + & $\mathrm{RS}$ \\
\hline & 4) Energy consumption per 10,000 yuan GDP & ton $(\mathrm{SCE})$ & - & SY \\
\hline & 5) Per capita nighttime lights & $\mathrm{nW} / \mathrm{cm}^{2} / \mathrm{sr}$ & - & $\mathrm{RS}$ \\
\hline \multirow{7}{*}{ Environmental } & 6) Ratio of industrial solid wastes comprehensively utilized & $\%$ & + & SY \\
\hline & 7) Ratio of wastewater centralized treated of sewage work & $\%$ & + & SY \\
\hline & 8) Industrial wastewater discharged per 10,000 yuan GDP & ton & - & SY \\
\hline & 9) Industrial sulphur dioxide emissions per 10,000 yuan GDP & ton & - & SY \\
\hline & 10) Industrial soot(dust) emission & ton & - & SY \\
\hline & 11) NDVI & & + & RS \\
\hline & 12) AOD & & - & RS \\
\hline \multirow{5}{*}{ Economic } & 13) Per capita GDP & yuan & + & SY \\
\hline & 14) Per capita annual disposable income & yuan & + & SY \\
\hline & 15) Registered rate of unemployment & $\%$ & - & SY \\
\hline & 16) Per capita fiscal income & yuan & + & SY \\
\hline & 17) Number of patent granted per 10,000 persons & unit & + & SY \\
\hline \multirow{5}{*}{ Infrastructure } & 18) Number of doctors per 10,000 persons & user & + & SY \\
\hline & 19) Number of beds in health care institutions per 10,000 persons & unit & + & SY \\
\hline & 20) Number of collections of public libraries per 100 persons & unit & + & SY \\
\hline & 21) Number of subscribers of mobile telephones per 100 persons & user & + & SY \\
\hline & 22) Number of subscribers of internet services per 100 persons & user & + & SY \\
\hline
\end{tabular}

SY refers to data obtained from statistical yearbook, RS refers to data obtained from remote sensing, + means positive indicator, means negative indicator

Shanghai, Guangzhou, and Shenzhen) to correct any outliers.

\section{Landsat8-OLI Data}

We extracted the areas' land cover types from the Landsat8-OLI data with the help of eCognition 9.0 software, which uses an object-based technique to classify RS imagery and has been proven to obtain satisfactory classification results [17-20]. In this study, our classification accuracy was better than $85 \%$ when compared with the ground truth points. Based on our classification results, we identified areas of developed and cultivated land and adopted these as resource indicators.

\section{Selection and Weighting of Indicators}

From an extensive literature review, we made a preliminary selection of 38 indicators. Then, based on expert advice and a correlation test, we ultimately chose 22 indicators for our RECC evaluation (see Table 1). To facilitate our analysis, we divided the indicators into four subcategories: resources, environment, economic, and infrastructure.

Before calculating the weight of the indicators, we needed to remove their dimensional effects, which we did by adopting the following equations:

For positive indicators:

$$
x_{i j}^{\prime}=\frac{x_{i j}-x_{j \min }}{x_{j \max }-x_{j \min }}
$$

For negative indicators:

$$
x_{i j}^{\prime}=\frac{x_{j \max }-x_{i j}}{x_{j \max }-x_{j \min }}
$$

...where $x_{i j}$ is the statistical or RS value of the $i$-th city for the $j$-th indicator, $x_{i j}^{\prime}$ is the normalized value of the $i$-th city for the $j$-th indicator, and $x_{j \max }$ and $x_{j \min }$ denote the maxima and minima of the $j$-th indicator, respectively. 
Based on these normalized values, to avoid any subjective influences we used an objective approach mean variance analysis - to determine the weight of each indicator. The details of this analysis procedure are as follows:

$$
\begin{gathered}
\mathrm{E}(j)=\frac{1}{m} \sum_{i=1}^{m} x_{i j}^{\prime} \\
\sigma(j)=\sqrt{\frac{1}{m} \sum_{i=1}^{m}\left(x_{i j}^{\prime}-E(j)\right)^{2}} \\
\omega_{j}=\sigma(j) / \sum_{j=1}^{n} \sigma(j)
\end{gathered}
$$

...where $\mathrm{E}(j)$ refers to the mean of the $j$-th indicator, $\sigma(j)$ is the standard deviation of the $j$-th indicator, and $\omega(j)$ is the weight of the $j$-th indicator.

Finally, we can determine the RECC using the following formula:

$$
R_{i}=\sum_{j=1}^{n} x_{i j}^{\prime} \omega_{j}
$$

\section{Results and Discussion}

\section{Spatial Features of AOD}

Fig. 2 presents the final AOD distribution. In this study, we used AOD data as an environment indicator, as it has been proven to accurately reflect air quality [21-23]. The AOD value of the southeast region of the

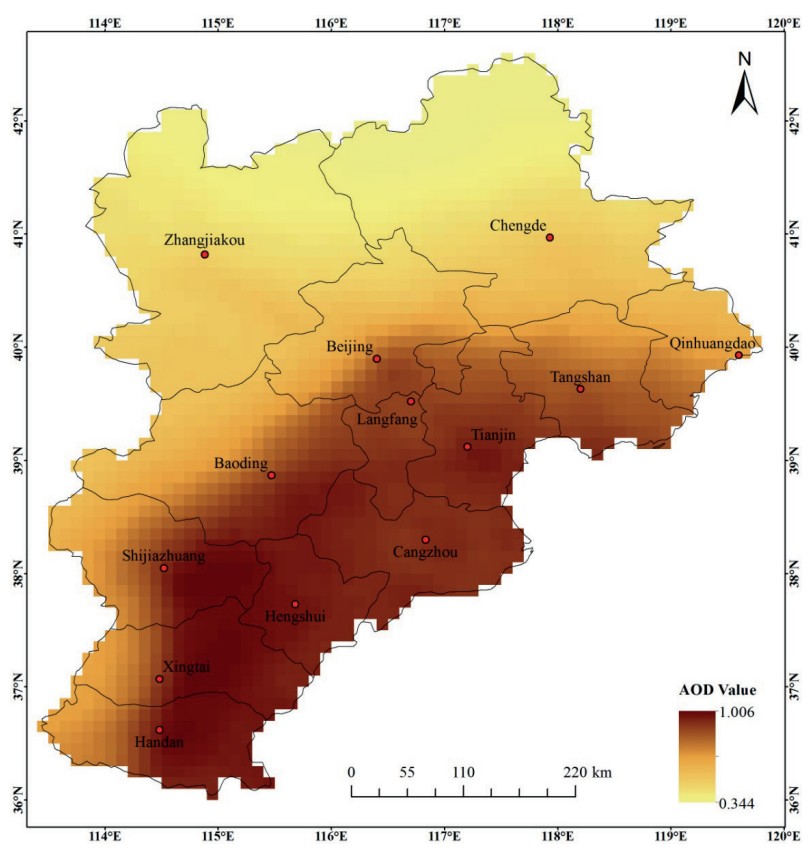

Fig. 2. AOD distribution in study area.

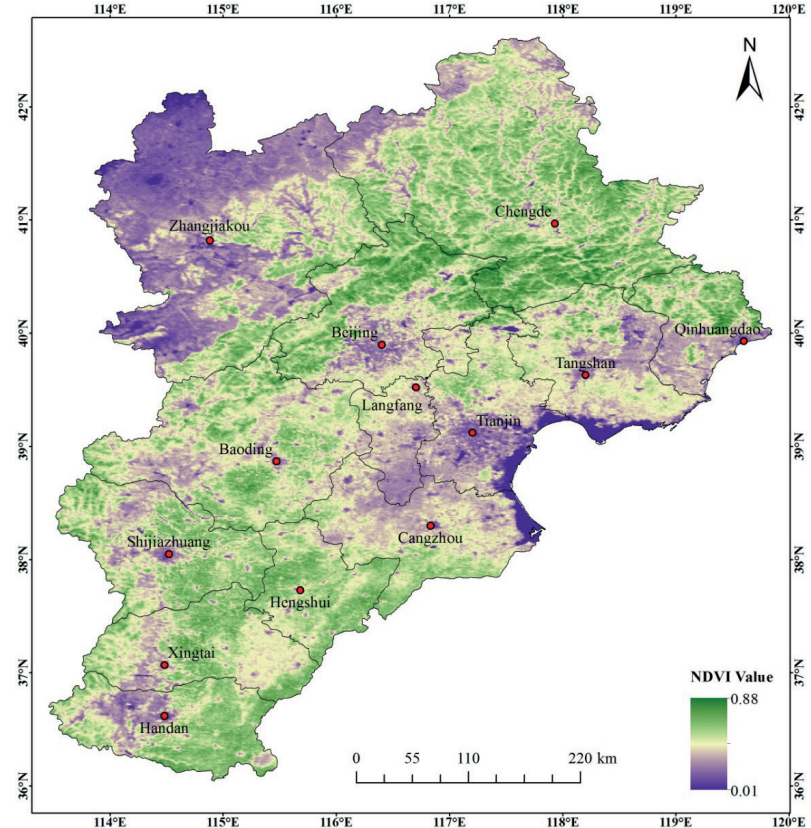

Fig. 3. NDVI distribution in study area.

study area is obviously higher than that of the northwest region, likely due to their different regional landforms. Specifically, most factories are located in the plain areas of the southeast region and these can lead to bad air quality, whereas the northwest region contains mountainous areas with few factories.

\section{Spatial Features of NDVI}

A number of studies have found the NDVI to reveal environmental conditions $[24,25]$, so we used the NDVI products for our environment index. Fig. 3 shows

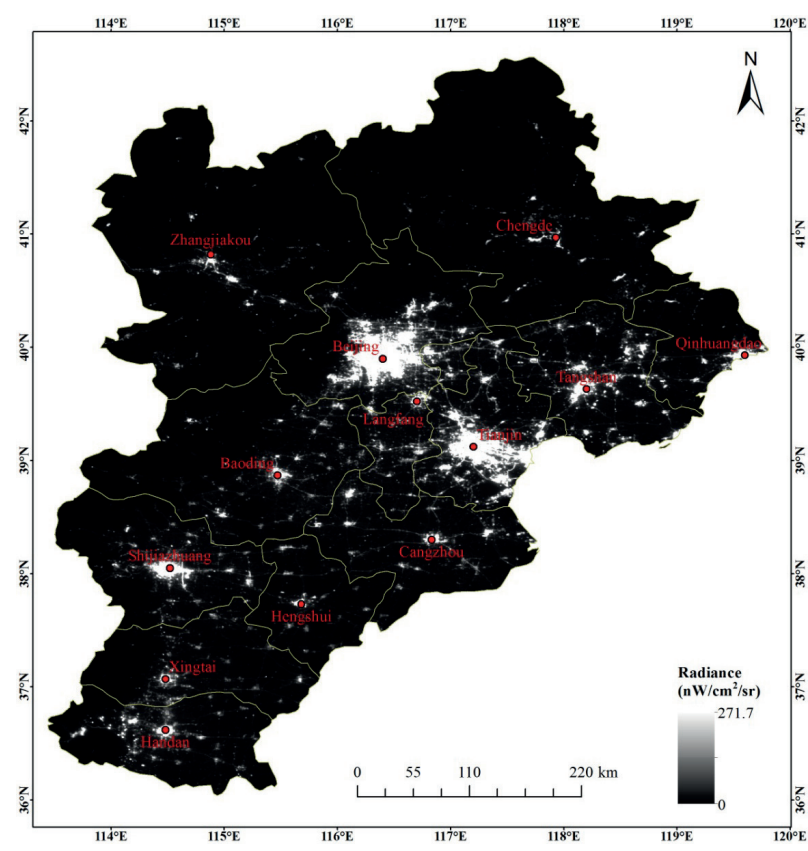

Fig. 4. NPP-VIIRS nighttime light data distribution in study area. 
the NDVI map, and we can see that the NDVI value is relatively low in built-up areas. Furthermore, the NDVI value of the northwest region is low due to the presence of massive desert areas and sparse grassland in Zhangjiakou. The low NDVI value in coastal regions is due to the water areas in Tianjin and Tangshan.

\section{Spatial Features of NPP-VIIRS Data}

Fig. 4 shows the corrected NPP-VIIRS imagery. As expected, urban areas have higher values than other areas. Since the use of nighttime lights data has been proven to be effective for estimating electric power consumption $[16,26]$, we used it in our study as a resource indicator.

\section{RECC Analysis}

Based on the above formulas, Table 2 lists the weight of each indicator. Some scholars have evaluated the importance of the subcategories by accumulating the weight of subordinate indicators $[12,27]$, but this approach is unreasonable when the quantity of indicators differs in each subcategory. In this paper, to estimate the significance of each subcategory we calculated the mean weight of its indicators. We can see from the table that, of the four RECC subcategories, environment has the largest mean weight at 0.0475 , followed by resources 0.0472 , economic 0.0452, and infrastructure 0.0410 .

Based on the values of the selected indicators and their weights, Table 3 presents the RECC and subcategory ranks of each city in the study area. A larger RECC value means a better state of development. The results show that Beijing has the highest rank and its RECC value is significantly higher than that of other cities. The RECC value of Beijing (0.757) is nearly threefold the minimum RECC value (0.282, Xingtai). In addition, to investigate the spatial distribution of the RECC in the study area, we used the natural breaks approach in Arcgis10.3 software to divide the RECC into four levels. Fig. 5 shows the RECC distribution map, from which we can conclude that the central and eastern cities have higher RECC levels than cities in the southern and northwestern regions.

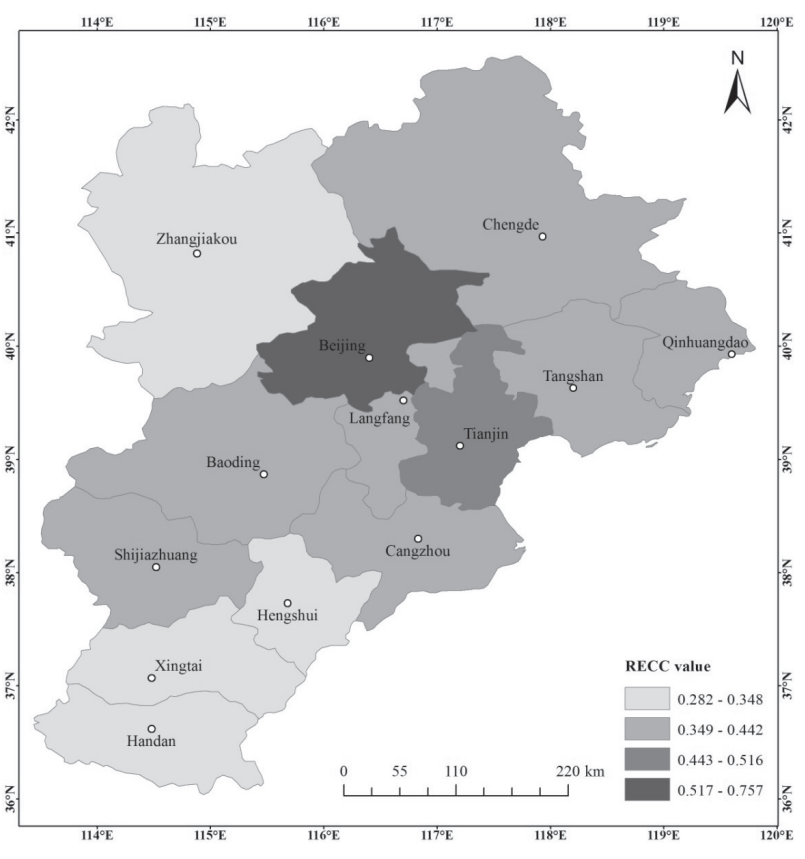

Fig. 5. Spatial distribution of RECC in study area.

On the basis of subcategory rank, we can further analyze the above results. First, despite the bad rankings of Beijing (11) and Tianjin (13) in the resources subcategory, they are ranked in the top three of the other three subcategories, which reveals that the RECC values of Beijing and Tianjin can be improved by importing external resources. Secondly, due to the more diversified and vitalized economies of the coastal regions, we can see that the economic conditions of the cities in this region (Qinhuangdao, Tangshan, Cangzhou) are superior to those in the inland regions (Zhangjiakou, Baoding, Hengshui, Xingtai, Handan). In addition, the municipalities (Beijing, Tianjin) and Shijiazhuang, the provincial capital, are ranked in the top five with respect to economic conditions because of advantageous government policies. Moreover, Langfang is ranked third highest in the economic subcategory due to its geographical position between Beijing and Tianjin, from which its economy undoubtedly

Table 2. Weight of each indicator.

\begin{tabular}{|c|c|c|c|c|c|c|c|}
\hline \multicolumn{2}{|c|}{ Resources } & \multicolumn{2}{c|}{ Environment } & \multicolumn{2}{c|}{ Economic } & \multicolumn{2}{c|}{ Infrastructure } \\
\hline Indicator & weight & Indicator & weight & Indicator & weight & Indicator & weight \\
\hline 1 & 0.0515 & 6 & 0.0454 & 13 & 0.0517 & 18 & 0.0384 \\
\hline 2 & 0.0465 & 7 & 0.0429 & 14 & 0.0433 & 19 & 0.0459 \\
\hline 3 & 0.0462 & 8 & 0.0412 & 15 & 0.0455 & 20 & 0.0415 \\
\hline 4 & 0.0411 & 9 & 0.0529 & 16 & 0.0426 & 21 & 0.0391 \\
\hline 5 & 0.0505 & 10 & 0.0502 & 17 & 0.0429 & 22 & 0.0403 \\
\hline & & 11 & 0.0490 & & & & \\
\hline Mean & 0.0472 & Mean & 0.0475 & Mean & 0.0452 & Mean & 0.0410 \\
\hline
\end{tabular}


Table 3. RECC rank of each city in study area.

\begin{tabular}{|c|c|c|c|c|c|c|c|c|c|c|}
\hline \multirow{2}{*}{ City } & \multicolumn{2}{|c|}{ RECC } & \multicolumn{2}{c|}{ Resources } & \multicolumn{2}{c|}{ Environment } & \multicolumn{2}{c|}{ Economic } & \multicolumn{2}{c|}{ Infrastructure } \\
\cline { 2 - 14 } & Result & Rank & Result & Rank & Result & Rank & Result & Rank & Result & Rank \\
\hline Beijing & 0.757 & 1 & 0.101 & 11 & 0.268 & 1 & 0.223 & 1 & 0.165 & 1 \\
\hline Tianjin & 0.516 & 2 & 0.082 & 13 & 0.229 & 2 & 0.124 & 2 & 0.082 & 3 \\
\hline Chengde & 0.442 & 3 & 0.182 & 1 & 0.182 & 8 & 0.028 & 8 & 0.050 & 6 \\
\hline Langfang & 0.433 & 4 & 0.117 & 9 & 0.200 & 6 & 0.075 & 3 & 0.042 & 7 \\
\hline Qinhuangdao & 0.421 & 5 & 0.128 & 5 & 0.173 & 9 & 0.036 & 6 & 0.085 & 2 \\
\hline Cangzhou & 0.398 & 6 & 0.121 & 8 & 0.217 & 3 & 0.029 & 7 & 0.030 & 9 \\
\hline Shijiazhuang & 0.394 & 7 & 0.084 & 12 & 0.214 & 4 & 0.039 & 5 & 0.057 & 5 \\
\hline Tangshan & 0.379 & 8 & 0.110 & 10 & 0.148 & 11 & 0.057 & 4 & 0.064 & 4 \\
\hline Baoding & 0.378 & 9 & 0.147 & 3 & 0.213 & 5 & 0.008 & 13 & 0.010 & 13 \\
\hline Zhangjiakou & 0.348 & 10 & 0.161 & 2 & 0.143 & 12 & 0.011 & 10 & 0.033 & 8 \\
\hline Hengshui & 0.342 & 11 & 0.133 & 4 & 0.182 & 7 & 0.010 & 11 & 0.017 & 12 \\
\hline Handan & 0.340 & 12 & 0.125 & 7 & 0.168 & 10 & 0.021 & 9 & 0.026 & 10 \\
\hline Xingtai & 0.282 & 13 & 0.126 & 6 & 0.126 & 13 & 0.009 & 12 & 0.022 & 11 \\
\hline
\end{tabular}

benefits. Thirdly, from the spatial distribution of the RECC, we can see that, interestingly, cities with the worst rankings have good resources. This demonstrates that there are obvious spatial imbalances between human and natural resources. Cities with the lowest RECC levels can promote their RECC by better developing themselves with respect to the other three subcategories, i.e., environment, economic, and infrastructure. According to the statistical data, we can also see that the economic condition of districts in Baoding city are ranked sixth, whereas Baoding has the lowest economic conditions. This suggests that differences exist both between and within cities.

\section{Analyzing Main Factors of Influence}

The values and spatial distribution of RECC themselves provide valuable information for the future development of each city in the study area. However, it is necessary to further investigate the factors having the greatest effect on the RECC. Many other studies have used correlation coefficients to determine the main factors influencing RECC [11, 28-29]. Here we used SPSS software and this same method to obtain the final results shown in Table 4. From the table we can see that 13 indicators have a statistically significant correlation with RECC and that indicator 16 (per capita fiscal income) has the largest correlation coefficient (0.835). As such, we can consider indicator 16 to be the most crucial factor influencing RECC.

\section{Effect of Indicator Selection Strategy on RECC Assessment}

We employed two indicator selection strategies to evaluate RECC. The first contains all the indicators mentioned above and the other contains 19 indicators, three of which (5-per capita nighttime lights, 11-NDVI, and 12-AOD) can only be obtained by RS data and were excluded. In this way, we explored the influence of indicators sourced from RS on RECC. From Table 5 we can see that the difference between these two RECC indicator selection strategies is not statistically significant.

Table 4. Correlation analysis between RECC and evaluation indicators of study area.

\begin{tabular}{|c|c|c|c|c|c|c|c|c|}
\hline Indicator & 1 & 2 & 3 & 4 & 5 & 6 & 7 & 8 \\
\hline Correlation coefficient & 0.275 & -0.187 & -0.313 & $0.643 *$ & $-0.747 * *$ & -0.033 & 0.198 & $0.582 *$ \\
\hline Indicator & 9 & 10 & 11 & 12 & 13 & 14 & 15 & 16 \\
\hline Correlation coefficient & $0.577 *$ & 0.549 & -0.154 & 0.335 & $0.780 * *$ & $0.593 *$ & $0.613 *$ & $0.835^{* *}$ \\
\hline Indicator & 17 & 18 & 19 & 20 & 21 & 22 & & \\
\hline Correlation coefficient & $0.599 *$ & $0.615^{*}$ & 0.308 & $0.709 * *$ & $0.797 * *$ & $0.676^{*}$ & & \\
\hline
\end{tabular}

** coefficient is significant at the 0.01 level; *coefficient is significant at the 0.05 level 
Table 5. Results of RECC with different indicator selection strategies.

\begin{tabular}{|c|c|c|c|c|c|}
\hline \multirow{2}{*}{ City } & \multicolumn{2}{|c|}{ RECC with RS data } & \multicolumn{2}{|c|}{ RECC without RS data } & \multirow{2}{*}{ Sig. } \\
\hline & Result & Rank & Result & Rank & \\
\hline Beijing & 0.757 & 1 & 0.787 & 1 & \\
\hline Tianjin & 0.516 & 2 & 0.592 & 2 & \\
\hline Chengde & 0.442 & 3 & 0.363 & 7 & \\
\hline Langfang & 0.433 & 4 & 0.464 & 3 & \\
\hline Qinhuangdao & 0.421 & 5 & 0.393 & 6 & \\
\hline Cangzhou & 0.398 & 6 & 0.402 & 4 & \\
\hline Shijiazhuang & 0.394 & 7 & 0.354 & 8 & \\
\hline Tangshan & 0.379 & 8 & 0.399 & 5 & \\
\hline Baoding & 0.378 & 9 & 0.321 & 9 & \\
\hline Zhangjiakou & 0.348 & 10 & 0.307 & 10 & \\
\hline Hengshui & 0.342 & 11 & 0.287 & 12 & \\
\hline Handan & 0.340 & 12 & 0.293 & 11 & \\
\hline Xingtai & 0.282 & 13 & 0.220 & 13 & \\
\hline Mean & 0.418 & & 0.399 & & 0.500 \\
\hline Standard deviation & 0.117 & & 0.149 & & 0.720 \\
\hline
\end{tabular}

Moreover, the RECC rank of each city has only a slight change, except for those of three cities (Chengde, Cangzhou, and Tangshan). However, we also find that the standard deviation of the result that included RS data $(0.117)$ is less than that without RS data (0.149). In addition, the difference between maximum and minimum RECC with RS data included (0.475) is also lower than that without RS data $(0.567)$. This reveals that indicators determined from RS data can more reasonably and stably assess RECC.

Although this study selected four aspects for assessment, due to data limitations we could not adequately consider institutional and perceptual aspects. Also, there is currently no explicit standard for constructing indictor systems and we look forward to eventually developing a comprehensive indicator system. Moreover, RS techniques have been utilized for broader applications, such as water quality assessment and water storage estimations [30-32], and we could use these to acquire more RECC assessment indicators. In future work, when we are able to collect additional relevant data, we can take these factors into account to gain a more comprehensive understanding of RECC.

\section{Conclusions}

In this study, we utilized both RS and statistical data to assess RECC. Using the mean-variance method, we determined the RECC value of the urban agglomerations of Beijing, Tianjin, and Hebei Province. Our research results were made more objective by the utilization of RS data and can provide valuable information for planners and managers, despite the relatively small influence of incorporating RS data. In terms of the overall conditions of each city in the study area, managers can adopt corresponding measures to improve their cities' RECC and thereby help them to develop in more sustainable directions. This process can also be applied to other regions.

\section{Acknowledgements}

This research was funded by the Special Project on High Resolution of Earth Observation System for Major Function Oriented Zones Planning (grant Nos. 00Y30B14-9001-14/16-1, 00-Y30B14-9001-14/16-2, and 00-Y30B14-9001-14/16-3) and the National Key Research and Development Plan (grant No. 2016YFC0503507-03).

\section{References}

1. PARK R.E., BURGESS E.W. An introduction to the science of sociology; The university of Chicago press: Chicago, USA. 1921.

2. GRAYMORE M.L.M., SIPE N.G., RICKSON R.E. Sustaining Human Carrying Capacity: A tool for regional sustainability assessment. Ecological Economics, 69 (3), 459, 2010.

3. NAVARRO JURADO E., TEJADA TEJADA M., ALMEIDA GARCÍA F., CABELLO GONZÁLEZ J., CORTÉS 
MACÍAS R., DELGADO PEÑA J., SOLÍS BECERRA F. Carrying capacity assessment for tourist destinations. Methodology for the creation of synthetic indicators applied in a coastal area. Tourism Management, 33 (6), 1337, 2012.

4. SALERNO F., VIVIANO G., MANFREDI E.C., CAROLI P., THAKURI S., TARTARI G. Multiple Carrying Capacities from a management-oriented perspective to operationalize sustainable tourism in protected areas. Journal of Environmental Management, 128, 116, 2013.

5. LANE M., DAWES L., GRACE P. The essential parameters of a resource-based carrying capacity assessment model: An Australian case study. Ecological Modelling, 272, 220, 2014.

6. NOOR A.M., QIAN Y., TANG L., QIU Q., XU T., LIAO J. A Comparative Analysis on Assessment of Land Carrying Capacity with Ecological Footprint Analysis and Index System Method. Plos One, 10 (6), e0130315, 2015.

7. DING L., CHEN K., CHENG S., WANG X. Water ecological carrying capacity of urban lakes in the context of rapid urbanization: A case study of East Lake in Wuhan. Physics and Chemistry of the Earth, Parts A/B/C, 89-90, 104, 2015.

8. WEI Y., HUANG C., LAM P., SHA Y., FENG Y. Using Urban-Carrying Capacity as a Benchmark for Sustainable Urban Development: An Empirical Study of Beijing. Sustainability, 7 (3), 3244, 2015.

9. TANG J., YE W. Study on environmental bearing capacity and its quantification. China Environmental Science. 1998.

10. FANG C., LIU X. Comprehensive measurement for carrying capacity of resources and environment of city clusters in central China. Chinese Geographical Science, 20 (3), 281, 2010.

11. YE W., XU X., WANG H., WANG H., YANG H., YANG Z. Quantitative assessment of resources and environmental carrying capacity in the northwest temperate continental climate ecotope of China. Environmental Earth Sciences, 75 (10), 2016v

12. WEI Y., HUANG C., LI J., XIE L. An evaluation model for urban carrying capacity: A case study of China's mega-cities. Habitat International, 53, 87, 2016.

13. SHI Y., WANG H., YIN C. Evaluation method of urban land population carrying capacity based on GIS - A case of Shanghai, China. Computers, Environment and Urban Systems, 39, 27, 2013.

14. LIU X., JIANG D., WANG Q., LIU H., LI J., FU Z. Evaluating the Sustainability of Nature Reserves Using an Ecological Footprint Method: A Case Study in China. Sustainability, 8 (12), 1272, 2016.

15. PENG J., DU Y., LIU Y., HU X. How to assess urban development potential in mountain areas? An approach of ecological carrying capacity in the view of coupled human and natural systems. Ecological Indicators, 60, 1017, 2016.

16. SHI K., YU B., HUANG Y., HU Y., YIN B., CHEN Z., WU J. Evaluating the Ability of NPP-VIIRS Nighttime Light Data to Estimate the Gross Domestic Product and the Electric Power Consumption of China at Multiple Scales: A Comparison with DMSP-OLS Data. Remote Sensing, 6 (2), 1705, 2014.

17. GAO Y., MAS J.F., MAATHUIS B.H.P., ZHANG X., VAN DIJK P.M. Comparison of pixel - based and object -oriented image classification approaches - a case study in a coal fire area, Wuda, Inner Mongolia, China. International Journal of Remote Sensing, 27 (18), 4039, 2006.

18. PU R., LANDRY S., YU Q. Object-based urban detailed land cover classification with high spatial resolution IKONOS imagery. International Journal of Remote Sensing, 32 (12), 3285, 2011.
19. MYINT S.W., GOBER P., BRAZEL A., GROSSMANCLARKE S., WENG Q. Per-pixel vs. object-based classification of urban land cover extraction using high spatial resolution imagery. Remote Sensing of Environment, 115 (5), 1145, 2011.

20. DURO D.C., FRANKLIN S.E., DUBÉ M.G. A comparison of pixel-based and object-based image analysis with selected machine learning algorithms for the classification of agricultural landscapes using SPOT-5 HRG imagery. Remote Sensing of Environment, 118, 259, 2012.

21. HIDY G., HOFF R., CHRISTOPHER S., SHARMA P., POULSEN T., KALLURI P., JENG F.-T. The A\&WMA 2009 Critical Review - Remote Sensing of Particulate Pollution from Space: Have We Reached the Promised Land? Journal of the Air \& Waste Management Association, 59 (6), 645, 2009.

22. WEBER S.A., ENGEL-COX J.A., HOFF R.M., PRADOS A.I., ZHANG H. An Improved Method for Estimating Surface Fine Particle Concentrations Using Seasonally Adjusted Satellite Aerosol Optical Depth. Journal of the Air \& Waste Management Association, 60 (5), 574, 2010.

23. GONG J., HU Y., LIU M., BU R., CHANG Y., BILAL M., REN B. Land Use Regression Models Using Satellite Aerosol Optical Depth Observations and 3D Building Data from the Central Cities of Liaoning Province, China. Polish Journal of Environmental Studies, 25 (3), 1015, 2016.

24. XU L.Y., XIE X.D., LI S. Correlation analysis of the urban heat island effect and the spatial and temporal distribution of atmospheric particulates using TM images in Beijing. Environmental Pollution, 178, 102, 2013.

25. DADVAND P., RIVAS I., BASAGAÑA X., ALVAREZPEDREROL M., SU J., DE CASTRO PASCUAL M., NIEUWENHUIJSEN M.J. The association between greenness and traffic-related air pollution at schools. Science of the Total Environment, 523, 59, 2015.

26. ZHUO L., ZHENG J., ZHANG X., LI J., LIU L. An improved method of night-time light saturation reduction based on EVI. International Journal of Remote Sensing, 36 (16), 4114, 2015.

27. CHENG G., SHEN L. Evaluation of urban synthetic carrying capacity of the Tianshan North-slope Urban Agglomeration. Journal of Desert Research, 35 (5), 1371, 2015 [In Chinese].

28. YE W., WANG H., XU X., WANG H., WANG H., WANG G. Quantitative analysis of resource and environment carrying capacity for Water Conservation Area in Qin-Ba Mountains. Chinese Journal of Eco-Agriculture, 23 (8), 1061, 2015 [In Chinese].

29. GUO K., WANG L. Change of resource environmental bearing capacity of Beijing-Tianjin-Hebei region and its driving factors. Chinese Journal of Applied Ecology, 26 (12), 3818, 2015 [In Chinese].

30. KUBIAK K.A., KOTLARZ J., MAZUR A.M. Monitoring cyanobacteria blooms in freshwater lakes using remote sensing methods. Polish Journal of Environmental Studies, 25 (1), 27, 2016v

31. FENG W., ZHONG M., LEMOINE J.M., BIANCALE R., HSU H.T., XIA J. Evaluation of groundwater depletion in North China using the Gravity Recovery and Climate Experiment (GRACE) data and ground-based measurements. Water Resources Research, 49 (4), 2110, 2013

32. DENG H., CHEN Y. Influences of recent climate change and human activities on water storage variations in Central Asia. Journal of Hydrology, 544 (November 2016), 46, 2016. 